\title{
The Impact of Light Pollution Education through a Global Star-Hunting Campaign \& Classroom Curricula
}

\author{
Constance E. Walker ${ }^{1}$ and Sanlyn Buxner ${ }^{2}$ \\ ${ }^{1}$ National Optical Astronomy Observatory, Tucson, AZ, USA, cwalker@noao.edu \\ ${ }^{2}$ Planetary Science Institute, Tucson, AZ, USA, buxner@psi.edu
}

\begin{abstract}
Results of a survey assessing the impact on respondents and their students from the worldwide, citizen-science light pollution campaign called GLOBE at Night and the accompanying environmental-astronomy-based curricula called Dark Skies Rangers are presented.
\end{abstract}

Keywords. Light Pollution, Citizen-Science, Public Outreach

Hosted by the U.S. National Optical Astronomy Observatory over the last 7 years, GLOBE at Night (www.globeatnight.org) is an international campaign to raise public awareness of the impact of light pollution by inviting citizen-scientists to measure their night sky brightness. As a follow-on to GLOBE at Night, Dark Skies Rangers (www.globeatnight.org/dsr/) is a set of environmental-astronomy-based lesson plans for grades 3 through 12. The activities teach the importance of proper lighting technology, light pollutions effects on wildlife and energy, and how to monitor the darkness of your sky. An externally administered and analyzed survey was conducted among educators and students to determine the effectiveness of the campaign and lessons and identify where improvements could be made. 17\%(or 102 of 585) educators completed the online survey in Spring 2012. Some survey results are described here.

Dark Sky Rangers activities are most often used for in-class astronomy units or in club or afterschool programs, but also in planetaria, nature-science centers, state/national parks and star parties. Survey respondents stressed the versatility of the activities for different audiences and venues. The top reported benefit from the Dark Skies Education workshops was increased awareness of light pollution issues (98\%), followed by teaching resources (81\%) and resources for dark sky advocacy (68\%). The Demonstrating Light Pollution and Shielding activity was the top-rated activity (62\%). When asked about the impact of doing the Dark Skies Rangers activities, $96 \%$ of the respondents and $76 \%$ of their students were likely to take action to reduce light pollution in their community.

$67 \%$ of the survey respondents and $81 \%$ of their students who participated in the GLOBE at Night citizen-science campaign made changes in their use of lighting in their homes. Changes included upgrading fixtures, turning off outside lights, reducing usage, using more energy efficient lights, utilizing motion sensors, being an advocate and educating others about light usage, becoming involved in policy making, and becoming more aware of community lighting. All but 1 respondent indicated they believed that engaging students in GLOBE at Night activities increased their understanding of light pollution.

Following the framework (http://insci.org/resources/Eval_Framework.pdf) used by the U.S. National Science Foundation for evaluating impacts of informal science education projects, there is evidence that Dark Sky Rangers and GLOBE at Night programs have long-term impact on several categories including 1) awareness, knowledge or understanding, 2) engagement or interest, and 3) behavior. For more details, see the authors' article by the same title in the 2013 ASP Conference Series on "Communicating Science". 